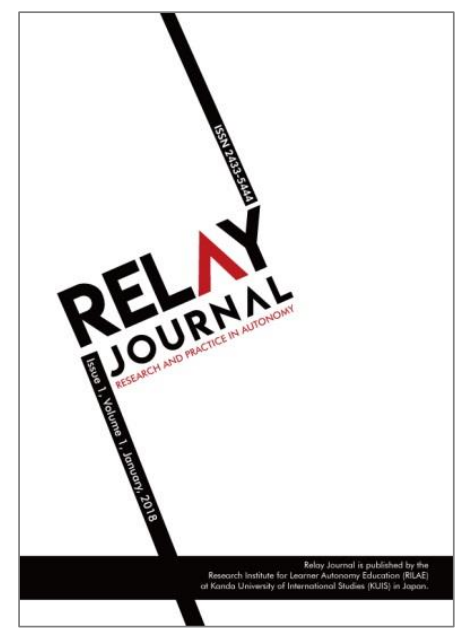

Relay Journal

https://kuis.kandagaigo.ac.jp/relayjournal

The Effect of Career Planning Tools in Developing Learning Autonomy

Charlotte Lin, Kanda University of International

Studies, Chiba, Japan

ISSN 2433-5444

To cite this article

Lin, C. (2018). The effect of career planning tools in developing learning autonomy. Relay Journal, 1(1), 147-158.

To link to this article

https://kuis.kandagaigo.ac.jp/relayjournal/issues/jan18/lin/

This article may be used for research, teaching and private study purposes. Please contact the authors for permission to re-print elsewhere.

Scroll down for article. 


\title{
The Effect of Career Planning Tools in Developing Learning Autonomy
}

\author{
Charlotte Lin, Kanda University of International Studies, Chiba, Japan
}

\begin{abstract}
This article reviews the career planning tools from each of the chapters in the book Taking Charge of Your Career Direction (Lock, 2005) and how these tools relate to developing learning autonomy. The main context of discussion is set in a Japanese university, where Japanese natives major in English and other languages, but the author also discusses how the tools apply to her own career development as an educator. In addition to discussing the usefulness of these tools from an educator's perspective, the article also makes suggestions on how these tools can be applied to students or anyone who is in a helping position of assisting university students to develop autonomy while navigating through life in university and beyond.
\end{abstract}

\section{Introduction}

For many people, the purpose of studying languages is to broaden the scope of their career opportunities. The lack of career motives or real-life application of the language can lead to a lack of learning motivation. Therefore, if explicit connection is made between language learning outcomes and the learner's potential career goal, there is a possibility that learning motivation and autonomy will increase. Anyone, not just young people, can use various career planning tools, at any point in their lives, to gain a deeper understanding of themselves and use that knowledge to refine their life or career goals at that time. Through the understanding of career goals, people can also define their language learning goals more clearly, and subsequently become capable of focusing their attention and energy in achieving those goals. In this critique, I will reflect on selected exercises and career development theories in each chapter of Taking Charge of Your Career Direction by Robert D. Lock (2005), and consider the results in the context of my current position of teaching English proficiency courses at Kanda University of International Studies (KUIS) in Chiba, Japan. Students at KUIS often aspire, from their first year, to build an international career with their academic training. For the most part, this means that the population I work with involve people who have "already decided on a career goal or education major...[but] are uncertain about how suitable this choice is" because they are still developing their career maturity, which is the "ability to make appropriate and informed career 
decisions, becoming aware of what is required to make career choices, and the degree to which those choices are realistic and consistent over time" (Lock, 2005, p. 4). In addition, I will provide key points of learning that are the most relevant, useful, and insightful from my perspective of being both a teacher and a life-long learner. The critique will conclude by linking various career planning tools to the development of learning autonomy, particularly in the language learning community.

\section{Chapter 1: Introduction to Career Planning}

It was useful to establish an early understanding between a job ("'a position of employment within an occupation”), an occupation (“one's vocation, business, calling, profession, or trade") and a career (“a sequence of a person's work experiences over time") (Lock, 2005, p. 2). I observe that the distinction between the three is not concrete to many, especially young people who are just starting to explore their career options. This understanding seems crucial, as they require different levels of planning. I find that most students seem to know what careers they want, but are unsure of the jobs they might need to start with to build up that career, or the various occupations that might exist within that career. This is why I find Lock's (2005) suggestion about combining a rational career planning process and imagination quite helpful for someone who is just starting to conceptualize their career. For example, Exercise 1-1, the Ideal Job Description, allows students to freely imagine what their ideal job would be like. The result can serve as a rough guide as students develop their careers further. Similarly, tools like the Vision Exercise (Government of Alberta, 2017) allows for freedom to explore one's mind, desires, and uncover hidden wishes that they might have supressed before. The Ideal Job Description provides even more categories and detailed directions than the Vision Exercise. I believe this is a great beginning discovery tool that generates results for subsequent career planning processes.

As for theories presented in this chapter, I particularly identified with the theory of planned happenstance. I particularly identified when Lock (2005) stressed that "there is still plenty of room for conscious, reasoned planning" (p. 5) even in the face of uncontrollable sociocultural conditions and unpredictable life events. Throughout my career, I have always approached my goals with the "designer" mindset, with thorough research and meticulous planning from multiple angles in order to address any environmental and sociocultural 
constraints in creative and flexible ways. As well, I actively seek out experts and opportunities to help me grow in the directions I want. I am also happy to talk to and learn from everyone - a lot of times, I meet the "experts" in unexpected circumstances because of this. Three main concepts sum up my learning approach: creative problem solving, bias towards action, and joyful learning across subjects and from everyone. I believe it is this approach to career development that has often led me to surprising circumstances that turn out to be great opportunities. Some people would call it luck, but we really create our own luck.

\section{Chapter 2: The Changing World of Work}

Sir Ken Robinson (2006) argues for a change in educational paradigm because of the extraordinary unpredictability of the future - nobody knows what the world would look like in five years "yet we are meant to be educating [the students] for it". Fast forward to 2018, this rate of change has grown perceivably faster due to the advances of mobile technologies, machine learning, and artificial intelligence. For example, in the three years that my current institution implemented the iPad curriculum, I can visibly see students' attitude change about how they see and use mobile technology in their daily lives, including education. Teacher training programs in Scandinavia, for example, are now preparing to include computer science and coding ability in their curriculum, which means the teachers need to learn new skills too (O. Viberg, personal communication, 2017). Recently, Bill Gates (Hincks, 2017) identified AI, energy and biosciences as the most promising fields for new graduates today. While the demand for AI jobs rises, Rainie and Anderson (2017) also discussed the future of jobs and career training in the face of machine automation. A lot of changes in the world of work seem to be driven by technological advances. Even the economic landscape at large might alter drastically (Rainie \& Anderson, 2017).

With the rapid change of our world in the tech age in mind, I see the methods and scenarios to learn about the world of work in the textbook to be too slow and traditional. A bigger emphasis on how to address the unpredictability of the future would add great value to future editions. However, would waiting for books to present such information be too slow in today's information landscape? Rainie and Anderson (2017) quote Justin Reich: "educators have always found new ways of training the next generation of students for the jobs of the future, and this generation will be no different." To me, one way to achieve this in our contemporary society 
would be to take learning outside the classrooms so that learning becomes a ubiquitous part of life. The priority of what we can learn in class would be to develop independent, creative, resourceful, self-directed life-long learners, who are engaged and interested in how the world is changing, and who can utilize creative problem solving skills to create opportunities for themselves in an unpredictable future.

\section{Chapter 3: Your Preferences in the World of Work}

The technical information about the various kinds of inventories and assessment for career preferences is very useful in this chapter (e.g. The Six Holland Personality/Environment Types, The Strong Interest Inventory, the Career Assessment Inventory, The Myers-Briggs Type Indicator and others). However, adding a discussion of the meaning of effective career assessments would make the results even more direct and applicable to learners' lives. The main reason why I say this is that some assessment tools, especially popular ones like the MyersBriggs Type Indicator $®\left(\right.$ MBTI $\left.{ }^{\circledR}\right)$, are controversial and have been branded as "meaningless" (Vox, 2015). How do we avoid making the assessments just like another "pseudoscientific" personality test on the Internet? I believe in order to make the assessment results meaningful and effective, a high level of interpretation and reflection should take place within a collaborative relationship between the teacher/advisor and the student. Even in the absence of a professional, the assessment taker should evaluate the results by carefully and critically applying them to their unique life situations, instead of believing them blindly, because the success of a career entails so much more than just one's personality. Sadly, this seems to be the expectation and assumption of a lot of test-takers, and they might equate, or even blame, their failures to the failure of the assessments.

This kind of misunderstanding stems from multiple problems. One thing could be the oversimplified versions of the aforementioned assessments that are made available widely on the Internet. Reducing something that is supposed to indicate or inform complex issues such as personalities or career development could easily lead to a loss of necessary information. Another thing could be the lack of education on what to expect from the tests and how to get the results properly interpreted. Also, we should all recognize that the tests could not possibly be comprehensive, reliable, or valid enough to diagnose everybody, as everybody can be the exception to the rules. Therefore, the best way to see the assessments is perhaps just exactly as 
they are - interesting, even entertaining, insights about ourselves. We could enjoy and debate about the results, but in the end, actually working and doing is what is really going to make our careers fruitful and, hopefully, successful.

In my current work context, I do think that doing some of these assessments with students serves an additional language-learning function. Students will be exposed to not only interesting information about themselves, but also learn the linguistic skills and various adjectives, nouns and verbs that could be used to describe themselves and their career choices. This could add to, for example, their English job interview skills for international positions.

\section{Chapter 4: Gathering Information about Your Occupational Prospects}

Recently a friend asked me why I am still actively reading the latest information about the creative industry. He wondered why I would even care if I am no longer working in that field. To me, the answer is obvious: in addition to satisfying my curiosity and need for knowledge, I like to keep updated about all my career prospects so that when the timing and opportunities are right, I would be ready. Learning about the current states of my preferred fields also allows me to reflect on my past choices and behaviours for the betterment of my future decision-making. His question did make me see that not everyone thinks about career preparation the same way. Lock (2005) describes that "gathering information about occupations that interest you is at the heart of the career-planning process. Career decisions are only as good as the information you bring to them" (p. 121). This statement highlights the importance of learning about prospective careers. My friend's question also made me see that young students may potentially miss this importance, or do not know how to gather necessary information in the first place.

For young students who may not have yet developed a learning/researching/reading habit for career information, the methods presented in Chapter 4 might appear overwhelming. I would perhaps get them started with Exercise 4-1: OOH Occupational Cluster Checklist to familiarize them with the 11 categories of occupational groups. However, I most likely will lead the students to conduct all other subsequent research (e.g. definition of specific jobs) online. To do this

professionally and effectively, however, it would be important for me to compile accredited online versions of the other exercises provided in this chapter. 


\section{Chapter 5: Motivation and Achievement}

Motivation, goal-setting, and needs analysis are frequent topics at my work because of our Self-Access Learning Center (SALC), which helps students develop self-directed learning skills along with their language proficiency courses. For Japanese students, goal setting is seldom developed before university because of the extreme teacher-centered, top-down approach in the K-12 public education. They therefore often ask questions like "how do I improve writing?" without thinking about what their goals for writings are. Goal setting, then, is crucial in the early stage of their academic training, which is in accordance with the sequence of goal achievement described by Lock (2005) - goal, motives, and needs. According to Lock (2005), goals are "any achievement toward which you direct your efforts"; motive, or motivation, is an "internal process that compels you to act in a purposeful way" (p. 178) to achieve the goals, and needs are where motivation stems from. Even when students understand the importance of goal setting, they do not yet know how to set goals and often start with very broad and abstract statements. I have done the SMART goal training for a couple of years now, and I am glad to see that measurable and short-term goals (Exercise 5-1) receive the same emphasis in the text as I do in my training. One additional activity that I do along with the SMART goal training is on how to design a short 7-day language challenge, where students can experience building mastery with small but consistent steps. I have not done any real research projects on this, but almost every student reports positive outcomes through such experiences and express the will to continue this method in their own time. This brings to me to the next point on motivation.

While extrinsic and intrinsic motivation are two types that are often discussed in language education, I personally believe that intrinsic motivation creates real, lasting effects. Pink (2009) identified autonomy, mastery and purpose as main aspects of intrinsic motivation that would ultimately maximize performance and satisfaction. Activities such as the SMART 7day challenge contribute to the development of all three aspects. I would postulate that such learning experiences, even grounded in the language-learning context, have the potential to develop into life-long learning habits that can be applied to learning other skills in the future.

\section{Chapter 6: Abilities: Skills and Aptitudes}

Continuing with the line of developing mastery, it is useful to consider the building blocks of mastery: abilities, skills and aptitudes. Lock (2005) defines ability as the "capacity to 
act with competence in an activity or occupation" and skill as "competencies developed from learning and practice" (p. 211). These definitions suggest that skills cannot be developed without the initial ability to act. Tim Ferriss is a productivity expert, who advocates that people can learn anything as long as they break down the desired skills analytically into frameworks that can be applied to personal capabilities and fears to produce high level learning and results (Ferriss, 2008). People might still get varying results based on their aptitudes, or "the capacity to learn" (Lock, 2005, p. 235), but I agree that the right materials and methods generally lead to satisfactory learning results. Personally, I believe while aptitudes contribute certain levels of achievement, it is ultimately practice, discipline, concentration, patience, a great concern for the desired goal (Fromm, 1956) and a growth mindset (Dweck, 2006) that would lead to the mastery of the subject.

For my work, I think Exercises 6-1 to 6-4 are excellent tools to help students learn how to verbalize their skills and learn the vocabulary associated with skills and careers. Even for native English speakers, this very specific way of describing skills is great for writing CVs and interviews, and future career planning. Out of the three categories, I find adaptive or selfmanagement skills the most interesting because they deal with "how" we adapt to different situations, environment, and most importantly, ourselves. Regardless, it is important to use the appropriate combination of the three categories to create a clear and strong "description of what you can do and how you do it" (Lock, 2005, p. 250).

\section{Chapter 7: Cultural, Personal, and Work Values}

Having the chance to identify and prioritize my work and personal values in this chapter was immensely insightful for me. It was also useful to consider the various cultural values. Because of my international upbringing and lifestyle, I am used to diversity and I sometimes find myself not considering cultural differences deeply because I tend to see all humans, at their core, as equals, and not separated or marked by cultures in superficial ways. This mindset has both positive and negative effects for my position as a helping professional. The positive aspect is that people generally feel very accepted, cared for, and free from judgement in their interaction with me. The negative aspect is that I might not be aware of the unique struggles associated with the Japanese culture. Culture-related issues are often out of people's control, as they tend to occur at the sociocultural level. During my time in Japan, I have communicated with young people 
without fully understanding their culture-related struggles. Exercises like the Occupation Prestige exercise can help me relate to the job rankings in my students' society, and help me relate to them more. In addition, my practice can be further improved if I make it clear to them that I am not an expert of their cultural context but I am willing to learn about it during our conversations.

Through the exercises for Personal Values and Work Values, I was happy to see that my personal values align with my work values greatly. I think I knew it before because I have always believed that work should be a joyful part of my life. However, it was very interesting to see my work values in a clear and concise list. A deeper investigation into how they connect to my various careers revealed to me that my desire to contribute to the world and other people in meaningful ways was the main reason why I left two careers before and am now very satisfied with my current position. For the students, these exercises would be a good guide for them to achieve a more balanced lifestyle.

\section{Chapter 8 \& 9: Focusing and Making Your Career Decisions}

When it comes to decision-making, I am decisive primarily because I am passion-driven, which allows me to see my goals clearly and consciously commit to them with ease. This can be applied to small and big things. For example, I have never applied to more than two universities or two jobs at one time. I know that I want something and whether I am in a good position of getting it. As a result, I am usually successful when I do apply. This also saves me a lot of energy and time from preparing unnecessary applications. To reiterate a previous point, some people might view it as luck, but for me it is a result of creating the conditions to maximize my chance of being immersed in things I love doing as well as being with like-minded people - success, if we define it as making enough money doing things and being with people we love, is usually just a side effect of these actions. Therefore, it would actually be quite strange if I had to go through exercises like Exercise 9-1 to inform me how to choose something. In my current work context, the "college" scenario would not apply because students are already enrolled in a university. However, I can see how it might be modified for choosing a career field or an occupation within a career, which would then be quite useful for the majority of the Japanese students who are neither familiar nor certain about their career possibilities. The other exercises in Chapter 8 and 9 are not very useful for me for similar reasons, but I do see a lot of value for my students. 
My coping pattern for risks is a mix of Unconflicted Adherence, Unconflicted Change and Vigilance (Lock, 2005) depending on specific life situations at a given moment. Compared to when I was younger, I am even more vigilant now when I plan my future career. At the moment, I have a large goal for after my tenure in Japan. I know two things: I want to help people realize their dreams and achieve freedom through creativity and design thinking (Kelley \& Kelley, 2013; Burnett \& Evans, 2016) and I want to be based in Stockholm. I am still figuring out what I will actually do, but even when the specifics are still being worked out, I am doing everything I can to move myself towards that direction, including learning about the markets, possibilities, key players, building personal and professional relationships in Stockholm whenever possible, learning about immigration procedures, and learning Swedish. I am confident and certain about this decision, but I am also terrified because I have never invested in something so much before doing it. What if it fails? The point about effective decision making involving "some intermediate level of stress" (Lock, 2005, p. 311) seems accurate to me. I believe this stress is necessary and good for real growth, and it helps me stay vigilant about my decisions.

Based on my own experiences, understanding our own decision-making style and coping pattern has allowed me to reflect on past experiences while moving towards the future. These insights will be equally valuable for my students as well.

\section{Chapter 10: Reality-Testing Your Career Choice}

No matter how much planning and preparation I do before working, the only way for me to truly reality-test a career is through the actual work experience. For example, I had two years of research experience both in labs and the field before going on a research trip in the Arctic. I thought I was ready, but the realities (e.g. isolation, lack of communication) still challenged me greatly during the actual field season, and eventually led to leaving my first graduate program. This is ultimately a good thing because the actual work experience allowed me to see what worked and did not work for me, and gave me the freedom to move on to find a more fitting career.

I strongly agree with many of the reality-based and action-oriented exercises in this chapter. However, if I had done them before I entered the fields I have chosen so far, I would probably still have entered them regardless of the results. This is because I believe in experiential learning, as long as the experiences do not cause self-harm or harm to others. That being said, I 
still find the exercises to be great tools to clarify and specify career plans. The effect is similar to making the SMART goals. I particularly liked the Force Field Analysis and the Time Sequence Career Plan. I believe that looking at one's negative attributes is not only healthy but also necessary for growth. Knowing the negative traits and their effects early on in the career planning process allows us to implement actions to "minimize or reverse negative forces" (Lock, 2005, p. 371).

An interesting thing to consider and add to the education section of the chapter is the future of education. Massive Online Open Courses (MOOC's) are continuing to develop, and online degrees will become more prevalent and valid. Along with the spread of Internet and mobile technology, this will drive down the cost of education and create widespread access to education for everyone. This probably then suggests that the methods presented in the book will quickly become outdated. The content of learning is also important. Information is now easily accessible through various forms of media, so different levels of flipped learning are already occurring in many classes. Instead of knowledge, skills such as learning how to learn, creative problem solving, and project-based learning, are becoming more important to do in class in a group setting where the teachers take the role of facilitators. Classrooms and teachers will not disappear, but the ways education is conducted are shifting rapidly.

\section{Concluding Thoughts}

By approaching my own career with the three main concepts I identified at the beginning of this critique, 1) creative problem solving, 2) bias towards action and 3) joyful learning from everyone and across subjects, I have gained so much insight, experience, and strength to help me continue on the journey as an educator. I am exploring new tools for personal and career development, such as design thinking. Instead of asking "what am I going to be when I grow up?", Burnett (2015) prods people to ask the less anxiety-reducing question "what do I want to be next?" I find this question to be neither optimistic nor pessimistic, but rather a possibilitycentered and action-oriented way of thinking about the future, and frameworks like design thinking can help propel the ideas into actions.

In my developing role as an educator and career advisor, I wish to continue encouraging my students to orient themselves and create conditions to maximize the chance for success. The issue of motivation and willpower comes up often. On this topic, Hardy (2017) asserts that "if 
you're required to use willpower, you haven't made up your mind." In other words, if you are trying to muster the willpower to work towards a goal, you are really working on the willpower, not the goal itself. This is essentially a waste of time and energy, but Hardy (2017) also suggests reasons why people might get stuck in the willpower stage, which include the lack of commitment due to insufficient desire for the goal, and not creating an environment that "makes your goals inevitable”. This process optimizes planned happenstance, and is yet another very subjective and action-oriented way of looking at goal setting and goal realization. However, before I can engage my students in such thinking and conceptualization about their futures, perhaps they would need to start by learning about themselves and the evolving world of work. The learning through this course, then, provides valuable technical knowledge of assessments that young career explorers can use to take those crucial first steps towards developing autonomy and take charge of their career directions. I am excited to add this book to my toolkit and look forward to applying this knowledge in my mission of helping to generate creative, joyful, and active life-long learners.

\section{Notes on the contributor}

Charlotte Lin is a lecturer at the English Language Institute at Kanda University of International Studies. With a background in environmental science, photography, languages and a strong interest in education, Charlotte completed an MSc in Applied Linguistics and CALL at Stirling University, UK (2013). She also became a certified career and academic advisor through the University of Calgary in 2017. Her current teaching and research concerns creative problem solving, design thinking for education, and user experience design for educational technologies.

\section{References}

Burnett, B., \& Evans, D. (2016). Designing your life: How to build a well-lived, joyful life. New York, NY: Alfred A. Knopf.

Burnett, B. (2015, December 27). Designing your life [Audio podcast]. Retrieved from http://www.cbc.ca/radio/tapestry/what-am-i-doing-with-my-life-1.3082096/designingyour-life-1.3082143 
Dweck, C. S. (2006). Mindset: The new psychology of success. New York, NY: Random House, Inc.

Ferriss, T. (2008, December). Smash fear, learn anything [Video file]. Retrieved from https://www.ted.com/talks/tim_ferriss_smash_fear_learn_anything

Fromm, E. (1956). The art of loving. New York, NY: Harper and Row.

Government of Alberta (2017). CAREERinsite: Career planning for your future. Retrieved from https://careerinsite.alberta.ca/careerinsite.aspx

Hardy, B. P. (2017). Willpower doesn't work. Here's how to actually change your life. Retrieved from https://journal.thriveglobal.com/willpower-doesnt-work-here-s-how-to-actuallychange-your-life-9fb9a85762ca

Hincks, J (2017, May 16). Bill Gates advises college graduates on today's most promising careers. Retrieved from http://fortune.com/2017/05/16/bill-gates-college-graduationadvice/

Kelley, T., \& Kelley, D. (2013). Creative confidence: Unleashing the creative potential within us all. New York, NY: Crown Business.

Lock, R. D. (2005). Taking charge of your career direction: Career planning guide, book 1 (5th ed.). Belmont, CA: Thomson Brookes/Cole.

Pink, D. H. (2009). Drive: The surprising truth about what motivates us. USA: Riverhead Books.

Rainie, L., \& Anderson, J. (2017, May 3). The future of jobs and jobs training. Retrieved from http://www.pewinternet.org/2017/05/03/the-future-of-jobs-and-jobs-training/

Robinson, K. (2006, June 27). Do schools kill creativity? [Video file]. Retrieved from https://www.ted.com/talks/ken_robinson_says_schools_kill_creativity

Vox (2015, October 8). Why the Myers-Briggs test is totally meaningless [Video file]. Retrieved from https://youtu.be/Q5pggDCnt5M 